\title{
EDUCAÇÃO, REPRESSÃO E PRINCÍPIO DO PRAZER*
}

Lenildes Ribeiro Silva**

\section{RESUMO}

Este texto objetiva explicitar uma reflexão sobre alguns pontos da teoria freudiana e do pensamento de Adorno, destacando-se a repressão dos instintos necessária ao processo civilizatório em contraposição à identificação do indivíduo com a realidade exterior e as promessas de satisfação ressaltadas pela sociedade capitalista. Nesse sentido a escolarização se distancia do sentido educativo que, para Freud, compreende repressão e sofrimento resultantes da tensão entre Eros e Morte, e, conforme Adorno ressalta, pressupõe resistência constituindo um ego forte, autônomo. A educação hoje, e especificamente a escola, se apresenta adequada ao princípio do prazer imanente a essa sociedade imediatista, no que tende a se contrapor à angústia e ao sofrimento conseqüentes do processo de repressão dos instintos essenciais à civilização. Pautada numa pseudo liberdade, a escola se faz repressora e autoritária à medida que contribui para a formação de um indivíduo adaptado, identificado com as bases da sociedade capitalista dominadora, individualista, contra as quais os esforços de uma educação que prima pela humanidade deveriam direcionar-se no sentido da não aceitação e da resistência. Um projeto educativo humanizador e civilizador deve estar ligada à repressão racionalizada, fundamental à sobrevivência do indivíduo e da própria civilização.

Palavras-chave: educação; resistência; civilização; identificação; assistencialismo.

Observando os desdobramentos da sociedade atual em que os indivíduos encontram-se cada vez mais conduzidos pelo imediatismo e autobenefício, torna-se perceptível uma ênfase no princípio do prazer, conceito desenvolvido na teoria freudiana ${ }^{1}$ que se baseia na incapacidade

* Artigo recebido em 12/3/2007 e aprovado em 25/5/2007.

** Doutoranda em História e Filosofia da Educação e pesquisadora no grupo PAIDÉIA, na Faculdade de Educação - Unicamp. E-mail: lenildesribeiro@hotmail.com 
de se contrapor à realidade por um ego forte, autônomo e, em nome de uma autopreservação falsa, o indivíduo adere ao exterior identificandose com ele, procurando estar distante do sofrimento imposto pelo processo civilizatório. Nessa sociedade, o indivíduo parece não precisar mais reprimir-se, pois a felicidade, ainda que apenas como promessa, é apresentada como algo possível de ser realizado nas mais diferentes situações como, por exemplo, na idéia de democracia, no consumismo e nas coletividades.

Neste texto, procuro explicitar um raciocínio em que a educação, e especificamente a escola, é refletida como uma instância que adequa ao princípio do prazer instaurado e restaurado pela sociedade capitalista, imediatista, no que tende a contrapor-se à frustração e ao sofrimento conseqüentes do processo de repressão dos instintos agressivo e libidinoso, repressão essa fundamental para a constituição da civilização, do indivíduo. A angústia, ligada à renúncia, essencial ao processo civilizatório, faz-se por meio da tensão existente entre instinto de vida e instinto de morte, instâncias jamais conciliadoras ou hierarquizadas, mas relacionadas, e que conferem ao indivíduo a possibilidade de, em nome da coletividade e de si mesmo, abrir mão de seu desejo individualizado, como condição primeira da sobrevivência do outro, de si mesmo e da própria civilização.

Para Freud (2002) há uma luta constante entre a civilização e os indivíduos para que esses instintos sejam controlados, o que ocorre numa ameaça de destruição da própria civilização e dele mesmo. À medida que o processo civilizatório se desenvolve, mais cresce conjuntamente a repressão e a ameaça de implosão da civilização pelo desejo suprimido. Segundo Freud, os esforços da civilização direcionam-se principalmente para a sublimação ${ }^{2}$ desses instintos, de forma que prevaleça não a vontade do indivíduo mais forte, porém, do grupo dotado de justiça e razão que resguarde o bem comum. Os homens, para Freud,

São criaturas entre cujos dotes instintivos deve-se levar em conta uma poderosa cota de agressividade [...] a civilização tem de utilizar esforços supremos a fim de estabelecer limites para os instintos agressivos do homem e manter suas manifestações sob controle por formações psíquicas reativas. (FrEUD, 2002, p. 67-68)

Os instintos são os maiores impedimentos da civilização humana, e os indivíduos tendem a voltar-se contra a civilização, contra a repressão, 
no sentido de buscar satisfazer seus instintos e se afirmarem diante da coletividade procurando a felicidade permutada pelo processo civilizatório.

Porém, a felicidade que o indivíduo busca na sociedade capitalista é falsa, visto ser pautada no princípio do prazer que não requer renúncia e assim, mesmo em nome da autopreservação, torna-se impossível de ser efetivada. A felicidade, para Freud, no processo civilizatório, não pode ser realizada por completo, pois supõe renúncia e conseqüentemente, angústia, sendo que, de outra forma, sem repressão, torna-se impossível, uma vez que precederia assim a destruição do próprio indivíduo no contato com o outro. Quando ressalta a necessidade da repressão para o processo civilizatório e a constante vigilância da civilização para garantir que essa repressão aconteça, Freud afirma o seguinte,

A existência da inclinação para a agressão, que podemos detectar em nós mesmos e supor com justiça que ela está presente nos outros, constitui o fator que perturba nossos relacionamentos com o nosso próximo e força a civilização a um tão elevado dispêndio [de energia]. Em conseqüência dessa mútua hostilidade primária dos seres humanos, a sociedade civilizada se vê permanentemente ameaçada de desintegração [...] a civilização tem de utilizar esforços supremos a fim de estabelecer limites para os instintos agressivos do homem e manter suas manifestações sob controle por formações psíquicas reativas. (Freud, 2002. p. 68)

Para a reflexão proposta, além da teoria freudiana, ater-me-ei a alguns pontos fundamentais do pensamento de Adorno, como a contraposição à identificação cega com o objeto, a fusão entre as realidades subjetiva e objetiva. Fundamental para a construção do raciocínio aqui proposto, a relação entre sujeito e objeto, ${ }^{3}$ explicitada por Adorno (1995), traz uma reflexão sobre a relação tensa entre essas instâncias, evitando sua separação ou junção. A separação entre o sujeito e o objeto resulta na fetichização ${ }^{4}$ e coisificação, na medida em que a realidade objetiva não se separa das apreensões individuais, assim como o sujeito constituído em determinado contexto histórico e social também torna-se influenciado pelo exterior.

Da mesma forma que a separação das instâncias objetiva e subjetiva, sua junção pode gerar a dissolução de ambas, pois o sujeito, 
ao identificar-se com a realidade objetiva, não consegue pensar para além do que ela apresenta, ou seja, como algo fetichizado, inquestionável e justificável por si mesma. Nesse sentido, Adorno (1995) expõe sua reflexão sobre o realismo exagerado, fetichizado, em que o sujeito, no processo de identificação, tem sua consciência coisificada, isto é, impedida de conhecer para além do que está determinado pela aparência do real. Assim, a realidade toma forma e vida, ao passo que, o sujeito é coisificado, preso e identificado com ela. Por outro lado, a realidade objetiva também é subsumida, pois não se deixa conhecer apenas pelo que apresenta em sua aparência, ou seja, seu movimento histórico, suas contradições jamais são desvelados num processo de fetichização da aparência dada. Dessa forma, sujeito e objeto, para Adorno,

encontram-se mediados reciprocamente: o objeto, mediante o sujeito, e, mais ainda e de outro modo, o sujeito, mediante o objeto. A separação torna-se ideologia, exatamente sua forma habitual, assim que é fixada sem mediação. O espírito usurpa então o lugar do absolutamente subsistente em si, que ele não é: na pretensão de sua independência anuncia-se senhoril. Uma vez radicalmente separado do objeto, o sujeito já reduz este a si; o sujeito devora o objeto ao esquecer o quanto ele mesmo é objeto. (ADORNo, 1995, p. 183)

Mediante os desdobramentos de uma sociedade que prima pela satisfação imediata, a tensão que precisa existir entre a realidade objetiva e a subjetiva, que as tornam constituídas e constituintes, é substituída pela exaltação do existente, a fetichização, e assim, a separação do sujeito da realidade objetiva, como se essa realidade fosse imune às apreensões individuais, tomando o caráter de curso natural ao invés da compreensão de sua construção histórica e material. Da mesma forma, por meio do realismo exagerado, a fusão entre sujeito e objeto acontece pela identificação com essa realidade naturalizada e fetichizada. Uma realidade que, conforme ressalta Marcuse (1966), promete ao indivíduo desviarse da angústia provocada pelo processo civilizatório, conduzindo, em nome da autoconservação, a autodestruição do indivíduo, a uma consciência coisificada, presa ao real. Nas palavras do autor, "como o conhecimento da verdade completa dificilmente conduz à felicidade, essa anestesia geral torna os indivíduos felizes" (p. 102). Nesse sentido, a felicidade não sendo possível mediante a percepção da realidade pela consciência verdadeira, o que traria desconforto e angústia, é prometida 
mediante o engano, de uma falsa consciência, identificando assim o indivíduo com as relações bárbaras e anticivilizatórias da sociedade administrada dessa forma, "o terror é assimilado com a normalidade, e a destrutividade com a construção" (MARCUSE, 1966, p. 100).

Na promessa de satisfação do desejo do indivíduo, a sociedade capitalista cria outros desejos, os quais não suprimem o instinto inicial cedido ao processo civilizatório, antes são apresentados como meio para a felicidade, a autoconservação e a satisfação. Totalmente identificado com essa ilusão, o indivíduo adere às coletividades, ao consumismo, às instituições, à indústria cultural. Nesse caso, a escola, conforme se faz ver nas políticas e nas práticas educacionais que se articulam mundialmente, é apresentada como participante de um todo administrado em que o indivíduo também é regido pelo princípio do prazer, pela satisfação individual, o que se faz na busca do sucesso, no incentivo à competição e concorrência, ou mesmo em atitudes assistencialistas do processo de ensino e aprendizagem, como a facilitação do conhecimento, da avaliação, das atividades.

A repressão como fator fundamental ao desenvolvimento de uma sociedade humana, dentro da constituição do desenvolvimento da sociedade capitalista, é subsumida pelo princípio do prazer em que o indivíduo tem a sensação de não precisar mais reprimir-se visto que seu desejo é transferido para formas aparentemente possíveis de se realizar. Para Freud, a renúncia ao instinto, princípio básico e indispensável à civilização, priva o indivíduo da felicidade plena resultando em sofrimento, dessa forma, é efetivada a luta entre o instinto de vida e instinto de morte que se tensionam, não sendo possível um vencer o outro. Ou seja, o indivíduo luta para sobreviver na civilização, porém faz-se necessário o instinto de morte, ou seja, a renúncia aos instintos, e a conseqüente angústia pela impossibilidade de sua realização. Uma tensão que não resolvida pressupõe a existência de um mal-estar característico da civilização, isto é, o indivíduo sempre quer voltar-se contra a civilização, constituindo os elementos anticivilizatórios que ameaçam implodir a própria civilização que os gerou. Assim,

o natural instinto agressivo do homem, a hostilidade de cada um contra todos e a de todos contra cada um, se opõe a esse programa de civilização. Esse instinto agressivo é o derivado e o principal representante do instinto de morte, que descobrimos lado a lado de 
Eros e que com este divide o domínio do mundo. Agora, penso eu, o significado da evolução da civilização não mais nos é obscuro. Ele deve representar a luta entre Eros e a Morte, entre o instinto de vida e o instinto de destruição, tal como ela se elabora na espécie humana. Nessa luta consiste essencialmente toda a vida, e, portanto, a evolução da civilização pode ser simplesmente descrita como a luta da espécie humana pela vida. (Freud, 2002, p. 81-82)

A prevalência de um desses instintos sobre o outro resulta na morte do indivíduo, ou seja, em nome da felicidade plena e da sobrevivência a qualquer custo, o indivíduo entrega-se puramente ao instinto de morte, pois, sem repressão, não há indivíduo, vida ou civilização.

$\mathrm{Na}$ sociedade moderna, porém, há uma tentativa de inversão ou conciliação dessas duas instâncias, em que o indivíduo, não renuncia, antes transfere seu desejo para formas apresentadas como possíveis de conduzirem-no à felicidade. Uma das formas que a sociedade capitalista apresenta para desviar o indivíduo do sofrimento pela repressão é apresentada por meio do consumo, no qual, a sensação de desejo satisfeito advindo da aquisição da mercadoria, gera conseqüentemente outras inquietações, desejos e aquisições, pois, o desejo anterior, impelido pelo processo civilizatório, não foi possível de ser satisfeito, tornando-se uma promessa que não pode ser efetivada dentro da civilização.

$\mathrm{Na}$ impossibilidade da felicidade prometida, o indivíduo é conduzido pelo princípio do prazer imediato como superação da angústia gerada pela repressão no processo civilizatório. Assim, se faz possível a conciliação do desejo instintivo com os seus produtos e a promessa de satisfação. Dessa forma, assim, os artifícios apresentados pela sociedade, seja no consumismo, seja na indústria cultural, ou na busca cega e individual pelo sucesso, são apresentados constantemente ao indivíduo como substitutos da segurança e da felicidade que não se efetivou. Assim, nessa busca acirrada pela satisfação e felicidade individual, os indivíduos aderem às esquematizações da sociedade e a civilização rende-se à barbárie, contrapondo ao que antes objetivava. $\mathrm{O}$ indivíduo, à medida que busca sua satisfação, paga essa repressão com a ilusão de liberdade e autonomia. Conforme aponta Marcuse,

A repressividade do todo reside em alto grau na sua eficácia: amplia as perspectivas da cultura material, facilita a obtenção das necessidades da vida, torna o conforto e o luxo mais baratos, atrai áreas cada 
vez mais vastas para a órbita da indústria - enquanto, ao mesmo tempo, apóia e encoraja a labuta e a destruição. $\mathrm{O}$ indivíduo paga com o sacrifício do seu tempo, de sua consciência, de seus sonhos; a civilização paga com o sacrifício de usas próprias promessas de liberdade, justiça e paz para todos. (MARCuSE, 1966, p. 99)

A fuga da repressão acontece quando o indivíduo adere ao princípio do prazer a fim de lidar com a realidade de maneira imediatamente prazerosa. Tal fuga acontece em nome da autoconservação do indivíduo, o que pressupõe uma identificação imediata com o estabelecido e a perda da tensão entre sujeito e objeto. Essa autoconservação, no entanto, ao contrário de sua promessa, traz a morte do sujeito, ou seja, se o instinto de vida pressupõe o de morte no sentido da repressão em nome da conservação do sujeito, a adequação pura, sem repressão, é a superação do instinto de vida pelo de morte, ainda que em nome da autoconservação. Nesse sentido, a civilização que não está pautada na tensão existente entre vida e morte para sua manutenção, se autodestrói quando não renuncia na busca do prazer imediato. Marcuse (1966) faz uma reflexão sobre essa tensão entre o instinto de vida e o de morte, destacando que a prevalência do instinto de vida, ainda que de modo paradoxal, ocorre em morte pela impossibilidade dos instintos de os indivíduo serem satisfeitos na civilização.

Se tivessem liberdade de perseguir seus objetivos naturais, os instintos básicos do homem seriam incompatíveis com toda a associação e preservação duradoura: destruiriam até aquilo que os unem ou em que se conjugam. O EROS incontrolado é tão funesto quanto a sua réplica fatal, o instinto de morte. Sua força destrutiva deriva do fato deles lutarem por uma gratificação que a cultura não pode consentir: a gratificação como tal e como fim em si mesma, a qualquer momento. Portanto, os instintos têm que ser desviados de seus objetivos, inibidos em seus anseios. A civilização começa quando o objetivo primário isto é, a satisfação integral de necessidades - é abandonado. (MARCUSE, 1966, p. 33)

Nesse raciocínio, faz-se perceptível a regência do princípio do prazer na sociedade capitalista em que há a tentativa de superar a tensão existente entre vida e morte, sujeito e objeto, oferecendo realidades prazerosas constitutivas de felicidade, ainda que em aparência. Em nome da individualidade, o indivíduo adere à lógica capitalista, fazendo com 
que os objetivos por ela enfatizados tornem-se seus. Nesse sentido, a individualização, a adesão persistem e superam a individuação, a autonomia. O indivíduo, na incapacidade de resistir diante do todo administrado e ainda regido pelo princípio do prazer, percebe na realidade objetiva o que corresponderia aos seus instintos, o que é reforçado pela concorrência e competição desmedidas, dominação e exploração necessárias à constituição e manutenção da sociedade capitalista. Dessa forma, ao invés de autonomia em face da administração geral da sociedade, o que seria fundamental para a individuação, acontece a fusão do sujeito com essa realidade, uma fusão que não passa apenas pela dominação do geral sobre o particular, antes é também buscada pelo próprio indivíduo pela correspondência com seu desejo e a possibilidade da satisfação individual sem sofrimento.

O que a sociedade apresenta é uma vida de felicidade plena, conciliando as instâncias antes em tensão, conciliação essa que traduz em morte do sujeito e da própria civilização. É o que Freud ressalta quando afirma que "uma satisfação irrestrita de todas as necessidades apresenta-se-nos como o método mais tentador de conduzir nossas vidas; isso, porém, significa colocar o gozo antes da cautela, acarretando logo o seu próprio castigo" (FreUd, 2002, p. 25). Quando o princípio do prazer prevalece sobre o princípio de realidade procura a junção entre o sujeito e a realidade, proclamando a morte do próprio sujeito em nome, paradoxalmente, de sua conservação. Dessa forma, a tendência de o sujeito entregar-se à coletividade o distancia daquilo que seria sua atitude superadora, ou seja, a resistência ao esquematizado, para o autor, "a pressão do geral predominante sobre toda particularidade, os indivíduos e as instituições individuais tentem a desintegrar o particular e o individual juntamente com sua capacidade de resistência" (ADORNO, 1974, p. 35). Contra essa adesão do sujeito deve servir a educação no sentido da subversão e superação do real.

No sentido de compreender os processos educativos na sociedade atual, e especificamente os desenvolvidos no espaço escolar, me reporto ao fato de que, para Adorno, educação não condiz com a conciliação, a identificação do indivíduo às forças sociais. Educação, nesse sentido, supõe resistência ao fato dado, de forma que, o indivíduo por ela reafirme a tensão existente entre sujeito e objeto, entre repressão, renúncia e princípio do prazer, instinto de vida e instinto de morte. Segundo Adorno, "A educação só teria pleno sentido como educação para a auto-reflexão 
crítica" (ADORNo, 1974, p. 35). Nesse sentido, educar compreende repressão, renúncia e rejeição da fusão entre indivíduo e realidade, logicamente, ao princípio do prazer enfatizado pela sociedade atual.

Para Freud (2002), a educação está ligada ao processo de repressão indispensável à civilização no sentido de que, por ela, o indivíduo é capaz de abrir mão de seus instintos em nome da coletividade. Nesse raciocínio, uma discussão torna-se fundamental em torno da educação que atende aos requisitos da civilização humana e da tensão entre instinto de vida e instinto de morte. Uma educação que contrapõe à identificação com a realidade objetiva e, portanto, na eliminação da tensão entre vida e morte pelo princípio do prazer ressaltado pela sociedade não opressora no sentido freudiano.

Nessa sociedade, o indivíduo tem necessidade de identificação com o exterior, com os grupos, necessidade essa que, mesmo vindo em nome da autoconservação, gera a destruição do indivíduo diante da adesão cega. Assim, ao contrário da autoafirmação, o indivíduo dessa adesão é, para Adorno (1995), portador de um ego fraco que, na impossibilidade de resistência, autonomia e negação, adere a fim de sentir-se participante. O indivíduo busca a segurança no grupo, nos líderes, e a eles se funde à procura da segurança antes conferida pela figura do pai, uma fusão que impede a formação de um ego forte, emancipado, não-identificado. Nas palavras de Adorno, “... atualmente a sociedade premia em geral uma não-individuação; uma atitude colaboracionista. Paralelamente a isso acontece aquele enfraquecimento da formação do eu, que de há muito é conhecida da psicologia como "fraqueza do eu" (p. 153). A partir dessa fusão, o indivíduo passa a rejeitar qualquer forma de apreensão, ação e pensamento que não esteja também identificado com aquela coletividade, conforme Adorno ressalta quando reflete sobre as manifestações bárbaras e preconceituosas na sociedade, a exemplo de Auschwitz.

Transpondo a idéia da identificação para a educação, e aqui especialmente para a escola, torna-se perceptível a correspondência com as apreensões e concepções, que envolvem o processo de ensino e aprendizagem com a realidade objetiva. A exaltação do existente acontece no interior da escola com a ênfase na preparação para o trabalho e mudanças da sociedade moderna. Assim, e de tal forma, que a escola passa a ser, ao contrário de um instrumento de resistência e subversão, um veículo de naturalização do desenvolvimento da sociedade capitalista, da técnica, do mundo do trabalho alienado. Pela escola, o indivíduo tem 
a ilusão de sentir-se participante. E assim como a escola prossegue na identificação com o real existente, a indiferenciação acontece a qualquer atitude ou concepção que não estejam também vinculadas à essa identificação. Nesse sentido, as políticas e ações para a escola não apenas são apresentadas vinculadas ao desenvolvimento da sociedade capitalista e a idéia de progresso científico e tecnológico advindo desse desenvolvimento, como também em rejeição ao pensamento e à crítica que busquem questionar e pensar a escola por uma outra via que não apenas a da adaptação. A relação da educação com a adaptação é, para Adorno, um processo ambíguo à medida que "a educação seria impotente e ideológica se ignorasse o objetivo de adaptação e não preparasse os homens para se orientarem no mundo" (AdORNo, 1995, p. 143), no entanto, ela não pode apenas servir à isso, visto que desta forma, preparariam apenas pessoas ajustadas sem corresponder ao seu caráter emancipador, verdadeiramente crítico.

A educação, nesse sentido, é reduzida ao espaço escolar, e suas discussões parecem estar muito bem determinadas a ponto de parecer inútil re-pensá-las. O que se tem a fazer diante disso é lançar mão das metodologias, da técnica, a fim de viabilizar uma prática em concordância com o mundo da competição individual e da adesão cega do indivíduo ao todo estabelecido.

O mesmo raciocínio que percebe a escola como identificada com o movimento da sociedade capitalista pode ser transferido para a identificação entre a escola e o indivíduo, o aluno. Nesse sentido, a escola, como uma instituição distanciada do processo de repressão e renúncia enfatizado por Freud, apresenta-se ao aluno como uma via pela qual a felicidade seja possível mediante a identificação deste com os processos educacionais. Segundo Zanolla (2002), no lugar das formas educativas explicitamente repressoras e autoritárias da escolarização de antes, o que se vê hoje é a efervescência de uma nova maneira de educar pautada no princípio do prazer. A escola hoje facilita o ensino e impede que o aluno atinja estágios de pensamento crítico e autonomia, por uma consciência coisificada. Se antes a escola pecava pelo autoritarismo, hoje ela o faz pela facilitação que não educa; antes, ilude o indivíduo com uma felicidade que não pode ser efetivada tornando o aluno mais vulnerável às adaptações, às indiferenciações, constituindo um ego fraco, tornando-se assim, pela aparência de não repressão, muito mais repressora que antes. 
Se, por um lado, a educação tradicional merece ser criticada pelo autoritarismo, por outro, a educação atual não merece crédito por confundir liberdade com libertinagem, autoridade com autoritarismo. A tendência paternalista da educação encontra na justificativa do 'prazer' um dos principais instrumentos de manutenção. (ZANOLLA, 2002, p. 115)

A repressão transvestida de liberdade é regida pelo princípio do prazer. Da mesma forma, a possibilidade da satisfação imediata, sem repressão, renúncia, pela incapacidade de lidar com a frustração, com a angústia pela repressão essencial à constituição da civilização e do próprio indivíduo, o conduz à identificação, como promessa de satisfação. Ao contrário da angústia gerada pela repressão, o conformismo gera sensação de prazer e felicidade, sendo, porém, muito mais repressor que antes. A educação escolar assistencialista faz com que o indivíduo, em nome de uma pseudoliberdade pela não repressão e promessa de satisfação e felicidade, torne-se muito mais preso à administração geral. Sobre essa liberdade, Marcuse ressalta os seguintes aspectos,

O que é repressivo não é a mecanização e padronização, mas a sua contenção; não a sua coordenação universal, mas o seu encobrimento sob liberdades, opções e individualidades espúrias. O elevado padrão de vida, no domínio das grandes companhias, é restritivo num sentido sociológico concreto: os bens e serviços que os indivíduos compram controlam suas necessidades e petrificam suas faculdades. Em troca dos artigos que enriquecem a vida deles, os indivíduos vendem não só seu trabalho, mas também seu tempo livre. A vida melhor é contrabalançada pelo controle total da vida. (MARCUSE, 1966, p. 99)

O assistencialismo do qual a escola lança mão para uma educação prazerosa condiz com uma sociedade patriarcal e com o retorno do Complexo de Édipo, ressaltado por Freud (1999), quando o autor busca relacionar a necessidade humana da religião com os antigos totens e a busca pela autoridade e segurança da figura paterna. Desde os tempos primórdiais o homem tem necessidade do patriarca, seja na figura dos deuses, seja do pai, seja dos elementos da natureza ou dos totens. Com o Complexo de Édipo, a morte da figura patriarcal faz com que o filho procure em outras figuras a segurança perdida. $\mathrm{O}$ indivíduo, ao invés de buscar sua autonomia, internalizando a autoridade perdida na construção de um ego forte, persiste em buscar nas coletividades, nos líderes, na 
escola, nos professores, a figura paterna a fim de sentir-se seguro, protegido, algo com que ele possa identificar-se, uma referência para sua própria identidade. O que ocorre, porém, é uma fusão com essa referência, que, em nome da identidade, conduz o indivíduo à perda de si mesmo, além de não conceber o outro como diferente de si.

No assistencialismo, a educação regida pelo princípio do prazer é autoritária no sentido de que impede a autonomia do indivíduo, sua identidade em nome de uma identidade aparente, uma pseudoautonomia, e é nessa aparência que essa educação torna-se mais repressiva que os processos explicitamente autoritários de antes. Ao contrário disso, a emancipação significa romper com o segundo Complexo de Édipo, ou seja, com o fato de o indivíduo procurar sua identidade num ego forte, não subsumido por qualquer figura exterior, antes mantém se a si mesmo no contato com o outro preservando a si e reconhecendo também o outro diferente.

Diante da constante barbárie que emana do próprio processo civilizatório pautado no desenvolvimento da lógica capitalista, a educação hoje, ao contrário do sentido educativo para a desbarbarização ressaltado por Adorno (1995), torna-se bárbara quando impede o crescimento, destitui o sujeito em nome da liberdade, da felicidade, do conhecimento e avaliações facilitados. A felicidade contínua não existe nem pode existir no processo civilizatório. Nesse sentido, é que instinto de vida e morte relacionam-se conflituosa e constantemente. A resistência em manter a tensão dessas instâncias, assim como toda tendência à reconciliação, à adaptação, estão ligadas ao princípio do prazer e, logicamente, à morte do sujeito ainda que buscada por ele mesmo. Contra isso, a educação ressaltada por Adorno (1995) deve se direcionar no sentido de que seja "uma educação para a contradição e a resistência" (p. 183), e, assim, seja conduzida no sentido do desenvolvimento da autonomia e renúncia ao totalitarismo da sociedade capitalista, que tende a subsumir o indivíduo de maneira cega e irracional no todo administrado com todas as contradições imanentes nessa administração. Nesse sentido, Adorno afirma que

a realidade se tornou tão poderosa que se impõe desde o início aos homens -, de forma que este processo de adaptação seria realizado hoje de um modo antes automático. A educação por meio da família, na medida em que é consciente, por meio da escola, da universidade teria neste sofrimento de conformismo onipresente muito mais a tarefa 
de fortalecer a resistência do que de fortalecer a adaptação. (ADORNO, 1995, p. 144)

Contra uma educação condizente com a dinâmica desumana e bárbara da sociedade atual, há que se observar e questionar as relações dos processos educativos dessa sociedade com a imanência do princípio do prazer ressaltado pela lógica capitalista e buscado pelo próprio indivíduo. Nessa perspectiva, faz-se necessário questionar as ações educativas que acontecem na escola, bem como suas políticas e discussões para compreender de que modo os discursos e as práticas da educação hoje aproximam-se ou afastam-se de um sentido educativo amplo que supere o totalitarismo da sociedade administrada para a constituição de um indivíduo autônomo e racional, em contraposição à construção da autonomia, se alia ao processo adaptativo imposto pela realidade social e buscado pelo indivíduo por meio do assistencialismo, da identificação e coisificação inerentes ao movimento da sociedade atual.

\section{ABSTRACT}

This paper has as its main objective to explain a reflection about some topics of the Theory of Freud and the thoughts of Adorno, emphasizing the repression of the primitive instinct that is necessary to the civilizing process in contraposition to the identification of the individual with an external reality and to the promises of satisfaction emphasized by the capitalist society. This way, the school educational system does not correspond to the educative sense that, according to Freud, comprehend repression and suffering as resultants of the tension between Eros and Death, and according to Adorno, it presupposes resistance constituting a strong ego, autonomous too. The Education, at the present time, presents itself, specifically in school, to be appropriate to the principle of immanent pleasure to this immediate society, as a tendency to oppose to the anguish and suffering that are a consequence of the repression process of a primitive instinct essential to the civilization. Focused on a pseudo-liberty, in the assistance, school is authoritarian and repressive as it contributes to the formation of the adapted individual, also identified with the bases of a masterful capitalist society, individualist, which bases go against the main efforts of a Education that is focused on humanity and it is addressed to the acceptance and not to resistance. An Educative and Civilizing process must be linked to a rationalized repression, which is essential to the surviving of the individual and the civilization itself.

Key word: education; resistance; civilization; identification; assistance. 


\section{NOTAS}

1. Sobre o princípio do prazer e sua impossibilidade de realização plena na civilização, Freud afirma que "esse princípio domina o funcionamento do aparelho psíquico desde o início. Não pode haver dúvida sobre sua eficácia, ainda que o seu programa se encontre em desacordo com o mundo inteiro, tanto com o macrocosmo quanto com o microcosmo. Não há possibilidade alguma de ele ser executado; todas as normas do universo são-lhe contrárias. Ficamos inclinados a dizer que a intenção de que o homem seja 'feliz' não se acha incluída no plano da 'Criação'. O que chamamos de felicidade no sentido mais restrito provém da satisfação (de preferência, repentina) de necessidades represadas am alto grau, sendo, por sua natureza, possível apenas como uma manifestação episódica. Quando qualquer situação desejada pelo princípio do prazer se prolonga, ela produz tão-somente um sentimento de contentamento muito tênue" (FreUd, 2002, p. 24).

2. Conceito explicitado por Freud relacionado à canalização do instinto primitivo e agressivo, impossíveis de serem realizados dentro do processo civilizatório humano, para formas culturais e socialmente aceitáveis, como o trabalho. Para Freud, "a sublimação do instinto constitui um aspecto particularmente evidente do desenvolvimento cultural; é ela que torna possível às atividades psíquicas superiores, científicas, artísticas ou ideológicas o desempenho de um papel tão importante na vida civilizada" (Freud, 2002, p. 52). Freud ressalta, no entanto, que a renuncia ao instinto, pelo processo de sublimação nem sempre é aceitável, causando o que vem denominar de "frustração cultural" e que, "como já sabemos, é a causa da hostilidade contra a qual todas as civilizações têm de lutar" (Idem).

3. Adorno critica a definição de sujeito e objeto isoladamente. A separação entre as instâncias subjetivas e objetivas, sem mediação de uma instância pela outra, torna-se ideologia. De outra forma, a junção promove identificação, o que também impede a abrangência tanto do sujeito como do objeto. "O objeto está tão longe de ser um resíduo desprovido de sujeito quanto de ser algo posto pelo sujeito. Ambas as determinações mutuamente hostis estão adaptadas uma à outra: o resto, com o qual a ciência se satisfaz como sendo a sua verdade, é produto de seu proceder manipulativo, subjetivamente organizado" (ADORNo, 1995b, p. 193).

4. Relaciono essa reflexão ao conceito de fetiche desenvolvido por Marx (2002), correspondente ao processo em que, o produto do trabalho, passa a existir fora das relações de produção, como mercadoria. Aquilo que o indivíduo imagina ser autonomiza e passa a fazer parte do próprio objeto, servindo assim diretamente ao desejo do sujeito. O fetiche da mercadoria se constitui num processo em que "[...] uma relação social definida, estabelecida entre 
os homens, assume a forma fantasmagórica de uma relação entre coisas. Para encontrar um símile, temos que recorrer à região nebulosa da crença. Aí, os produtos do cérebro humano parecem dotados de vida própria, figuras autônomas que mantém relações entre si e com os seres humanos. É o que ocorre com os produtos da mão humana, no mundo das mercadorias. Chamo a isso fetichismo, que está sempre grudado aos produtos do trabalho, quando são gerados como mercadorias" (MARX, 2002, p. 94).

\section{REFERÊNCIAS}

ADORNO, W. T. Sobre sujeito e objeto. In.: Palavras e sinais modelos críticos 2. Tradução de Maria Helena Ruschel. Petrópolis, RJ: Vozes, 1995.

Educação e emancipação. In: Educação e emancipação. Tradução de Wolfgang Leo Maar. São Paulo: Editora Paz e Terra, 1995a.

Educação - para quê? In: Educação e emancipação. Tradução de Wolfgang Leo Maar. São Paulo: Editora Paz e Terra, 1995a.

Educação após Auschwitz. In: COHN, G. (Org). Sociologia. São Paulo: $\overline{\text { Editora }}$ Ática, 1974.

FREUD, S. O futuro de uma ilusão. Tradução de José Octávio Aguiar Abreu. Rio de Janeiro: Imago, 1997.

FREUD, S. O mal-estar na civilização. Tradução de José Octávio Aguiar Abreu. Rio de Janeiro: Imago, 2002.

MARCUSE, H. Eros e civilização: Uma interpretação filosófica do pensamento de Freud. Tradução de Álvaro Cabral. 8. ed.. Rio de Janeiro: Editora Guanabara, 1966.

ZANOLLA, S. R. S. Teoria crítica e educação: considerações acerca do conceito de práxis. In: Educativa. v. 5, n.1. Goiânia: Editora da UCG, 2002. p. 107-118. 
